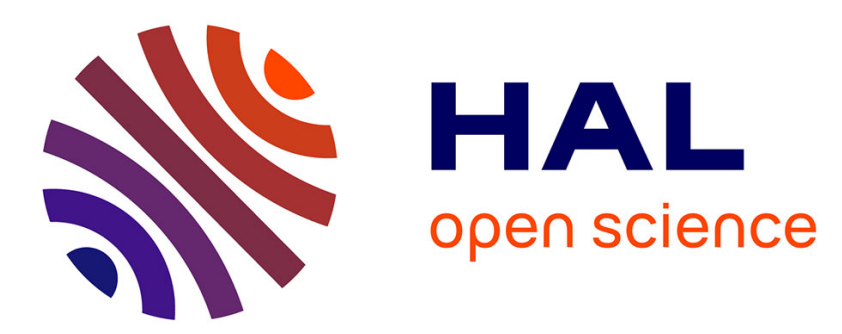

\title{
Imaging the mechanical properties of wood cell layers by atomic force modulation microscopy
}

Bruno Clair, Richard Arinero, Gérard Lévèque, Michel Ramonda, Bernard Thibaut

\section{- To cite this version:}

Bruno Clair, Richard Arinero, Gérard Lévèque, Michel Ramonda, Bernard Thibaut. Imaging the mechanical properties of wood cell layers by atomic force modulation microscopy. IAWA Journal, 2003, 24, pp.223-230. 10.1163/22941932-90001591 . hal-00004541v2

HAL Id: hal-00004541

https://hal.science/hal-00004541v2

Submitted on 22 Mar 2005

HAL is a multi-disciplinary open access archive for the deposit and dissemination of scientific research documents, whether they are published or not. The documents may come from teaching and research institutions in France or abroad, or from public or private research centers.
L'archive ouverte pluridisciplinaire HAL, est destinée au dépôt et à la diffusion de documents scientifiques de niveau recherche, publiés ou non, émanant des établissements d'enseignement et de recherche français ou étrangers, des laboratoires publics ou privés. 


\title{
IMAGING THE MECHANICAL PROPERTIES OF WOOD CELL LAYERS BY ATOMIC FORCE MODULATION MICROSCOPY
}

\author{
by \\ Bruno Clair ${ }^{1}$, Richard Arinero $^{2}$, Gérard Lévèque ${ }^{2}$, \\ Michel Ramonda $^{3}$ \& Bernard Thibaut ${ }^{1}$
}

Published in IAWA Journal, Vol. 24 (3), 2003: 223-230

\begin{abstract}
SUMMARY
Atomic Force Microscopy in force modulation mode has been used to study the elastic properties of the different cell wall layers of holm oak and boco. The method is based on the measurement of the resonance frequency of the microscope lever in contact with the sample. This frequency is related to the reduced Young modulus $E^{*}=E /\left(1-v^{2}\right)$ of the material, supposed to be isotropic. "Elastic" images of the cell are obtained, simultaneously with the topographic images, which allows the observation of the mechanical properties of the cells at a nanometric scale. Layers G, S1, S2 and ML are clearly distinguished. By comparison with known materials, an estimation of the absolute modulus is given in the range $5-20 \mathrm{GPa}$, but should be taken with care as the inherent anisotropy of the materials has not be taken into account.
\end{abstract}

Key words: wood, cell wall, mechanical properties, elastic modulus, atomic force microscopy.

\section{INTRODUCTION}

Mechanical properties of wood depend on the organisation and on the microscopic structure of its elements. Some of the macroscopic properties can be explain by the anisotropy or the porosity of the cells, but other properties as the growth stresses, the shrinkage or the specific modulus (ie Young modulus in longitudinal direction divided by specific gravity) find their clue essentially in the microscopic properties at the wall layers and in the cell structure.

\footnotetext{
${ }^{1}$ LMGC - Laboratoire de Mécanique et Génie Civil. UMR CNRS 5508

${ }^{2}$ LAIN - Laboratoire d'Analyse des Interfaces et de Nanophysique. UMR CNRS 5011

${ }^{3}$ LMCP - Laboratoire de Microscopie en Champ Proche Common address: Université Montpellier II, Place E. Bataillon, 34095 Montpellier, France

contact: clair@lmgc.univ-montp2.fr
} 
Using the estimated properties of wood constituents (lignin, hemicellulose, cellulose), the macroscopic elasticity of cell layers can be obtained by numerical simulation (Cave 1968; Yamamoto et al. 2001), but the in-homogeneity of the wood at various scales has to be correctly introduced. In particular the orientation of the cellulose microfibrilles in the lignin and xylan matrix influences strongly the microscopic properties of the different layers composing the wood cells (Harrington et al. 1998; Watanabe \& Norimoto 2000).

Local measurements by nanoindentation reported in Wimmer and Lucas (1997) and Wimmer et al. (1997), show the fact that mechanical properties of each cell layer can be estimated, at least those with sufficient thickness to be considered as semiinfinite at the scale of the punch.

In this study, we use an Atomic Force Microscope (AFM) to estimate the elastic modulus of the wood at a nanometric scale, using the technique introduced by Yamanaka and Nakano (1996) and Rabe et al. (1996) and called Force Modulation Microscopy or Acoustic Force Microscopy. In these experiments, the AFM cantilever is used as a resonator which frequency is function of the interaction between the tip and the sample. It permits to map the elastic properties of surface, thanks to a model based on the mechanics of contact, with the same resolution as the topography.

The technique as been used on different types of materials, as alloys, silicon devices, carbon fibres in an epoxy matrix, polymers, ADN molecules and living biological cells (Sasaki et al. 1998).

\section{MATERIAL AND METHODS}

\section{Experimental set-up}

The used device is a commercial AFM (Digital Instruments Nanoscope 3100) working in contact mode, i.e. tip is in contact with the sample (Fig.1). The lever geometry is described by its length $(\mathrm{L}=130 \mu \mathrm{m})$, its width $(\mathrm{W}=35 \mu \mathrm{m})$ and its thickness $(\mathrm{h}=1 \mu \mathrm{m})$, it presents a weak rigidity $(\mathrm{k}=0,67 \mathrm{~N} / \mathrm{m})$ and a free oscillation frequency of $65 \mathrm{kHz}$. The tip length is about $15 \mu \mathrm{m}$ and the radius at the apex is in the order of $\mathrm{R}=30 \mathrm{~nm}$ for a new tip, and increases by wear up to $\mathrm{R}=600 \mathrm{~nm}$. Lever and tip are in crystalline silicon, coated with a thin WC layer in order to minimise its wear.

The contact force between the tip and the sample is detected with a laser beam that reflects on the lever and is received by photodiodes. During the scan on the sample, the feedback of the microscope maintains a constant contact force. This allows acquiring the topography of the surface, by recording the movements of the piezoelectric actuators during the scans.

Simultaneously, a periodic force is applied on the lever, by mean of an electrostatic potential applied to the sample holder. When excitation frequency is close to the proper frequency of the lever a resonance occurs. The resonance frequency is related to the geometry and the stiffness of the contact, which can then be deduced. 


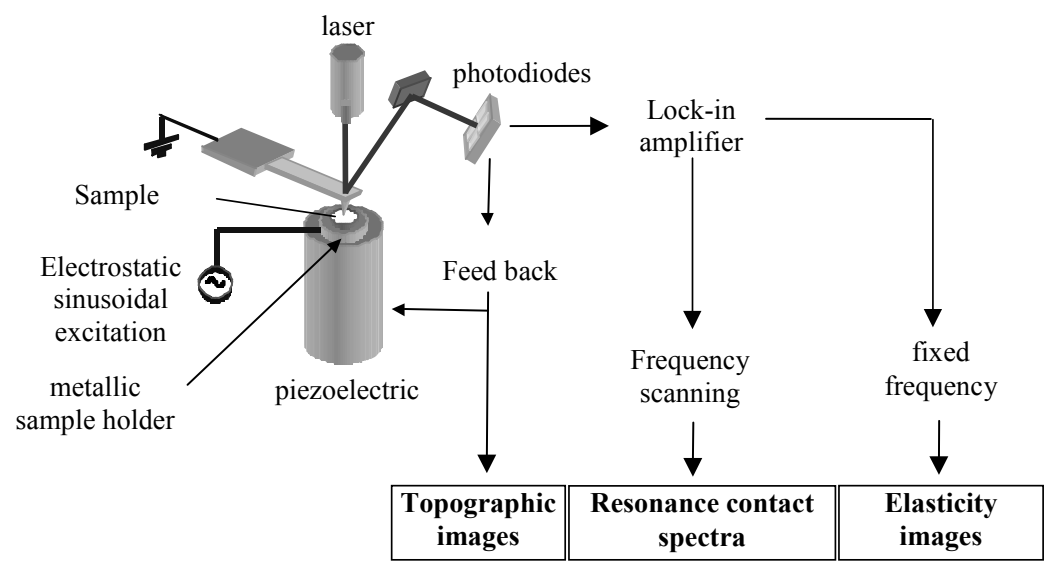

Fig.1. Schematic representation of an atomic force microscope in force modulation mode.

The lever oscillation frequency (in the $500 \mathrm{kHz}$ to $1 \mathrm{MHz}$ range) being very superior to the force feedback response, topographic information can be separate from local variations of the mechanical property, then the sample stiffness and topography can be collected simultaneously.

Quantitative analysis

The equations governing the oscillation of the cantilever and the tip are thoroughly analysed by Rabe et al. (1998), Yamanaka and Nakano (1998), Pietrement and Troyon (2000b) and Dupas et al. (2001). For each cantilever a master curve can be build, relating the resonance frequency to the contact impedance "s" on the sample. The Hertz or DMT contact theories (Maugis 2000; Pietrement \& Troyon 2000a) permit then, an evaluation of the reduced elastic modulus $E^{*}$ of the sample, assuming an isotropic sample and a rigid tip :

$$
s=\frac{d F}{d \delta}=\frac{d}{d \delta}\left(\frac{4}{3} E^{*} R^{1 / 2} \delta^{3 / 2}\right)=2 E^{*} R^{1 / 2} \delta^{1 / 2}=(6 E * 2 R F)^{1 / 3}
$$

$\mathrm{R}$ is the tip radius, $\delta$ the penetration, $\mathrm{F}$ the contact force, and $\mathrm{E}^{*}$ the reduced Young modulus (indentation modulus) $\mathrm{E}^{*}=\mathrm{E} /\left(1-\mathrm{v}^{2}\right)$. The tip is here supposed as perfectly rigid. Note that the contact force $\mathrm{F}$ includes the known applied force, the adhesion + capillary forces, and the mean electrostatic force used to excite the cantilever. The total force is estimated for each experiments (by pulling away the tip up to break the contact) and range between 10 and $100 \mathrm{nN}$, depending on the tip apex conditions.

Many sources of uncertainty arise in the experiments. First of all is the uncertainty of the cantilever characteristics as given by the constructors, dispersion of a factor 2 is common for the cantilever stiffness. Secondly, the exact shape of the tip apex may differ notably from a sphere (even for a new tip) and may evolve by wear during the 
scans towards a flatter surface. The effective radius of curvature of the tip goes typically from $30 \mathrm{~nm}$ up to $600 \mathrm{~nm}$ during the course of an experiment, even with a hard WC coating although the diameter of the contact zone remains below $50 \mathrm{~nm}$. Obtaining an image with a constant radius is not so easy and regular tip exchange and subsequent re-calibration are needed.

In conclusion, calibration of the elastic properties of the sample cannot be done by using theoretical models only, but need to be compared to standard samples of known properties. For this purpose we have selected and measured (by acoustic methods) several homogeneous samples, witch properties encompass the wood expected values : gold $\left(\mathrm{E}^{*}=95 \mathrm{GPa}\right)$, Pyrex glass $\left(\mathrm{E}^{*}=62 \mathrm{GPa}\right)$, sulphur $\left(\mathrm{E}^{*}=13\right.$ $\mathrm{GPa})$, PMMA $\left(\mathrm{E}^{*}=6.5 \mathrm{GPa}\right)$ and Polyurethane $\left(\mathrm{E}^{*}=0.28 \mathrm{GPa}\right)$ samples. For the last two material, which are visco-elastic polymers, the mechanical properties are measured at the working frequency, near $500 \mathrm{kHz}$.

The properties of the wood are then obtained by interpolation, with a master curve fitted on the known samples.

\section{Material and samples preparation}

Measurements have been realised on holm oak (Quercus ilex L.) wood in a zone including fibres with gelatinous layer where both $\mathrm{G}$ and $\mathrm{S}_{2}$ layers are thick. Other measurements have been done on boco (Bocoa prouasensis Aubl.) from french guyana. Holm oak and boco are both species interesting for turnery with very thick fibre cell walls.

A small sample is produced and glued perpendicularly to the fibres on the sample holder by cyanoacrylate glue (gel form). The four faces of the sample are then cut to give the shape of a cube $1 \times 1 \times 1 \mathrm{~mm}^{3}$. A final surface state is given to the superior face with a new disposable microtome blade.

The upper surface state must be as flat as possible, because too much relief would modify the contact surface between the tip and the sample and affect the elastic measurements. One can observe this effect in the G layer on the left top cell in Fig 3 were undulation of stiffness appears.

The wood samples are cut in air dry conditions and measures are made after stabilization of the sample in ambiant air.

\section{RESULTS and DISCUSSIONS}

Experiments on the wood samples have been performed in three steps.

First, we choose an excitation frequency for which amplitude variations permit to generate contrast, and scan the sample at this frequency. A picture of "elastic contrast" is recorded, as the oscillation amplitude of the cantilever during the topographic scans. At the scan velocity, a picture is acquired in around one hour. Secondly, a scan in frequency is performed at some fixed point on the sample, in order to measure precisely the resonance frequencies.

Thirdly, the resonance frequency on the standard samples are measured.

For valid results, the applied force and tip shape must not have changed during the three steps, the last condition appearing to be the most difficult to achieve. Examples 
of curves of the amplitude versus frequency are presented in Fig 2, for a typical cell (4 points on $\mathrm{G}$ layer, 4 on $\mathrm{S}_{2}, 2$ on $\mathrm{S}_{1}$ and 2 on middle lamella).

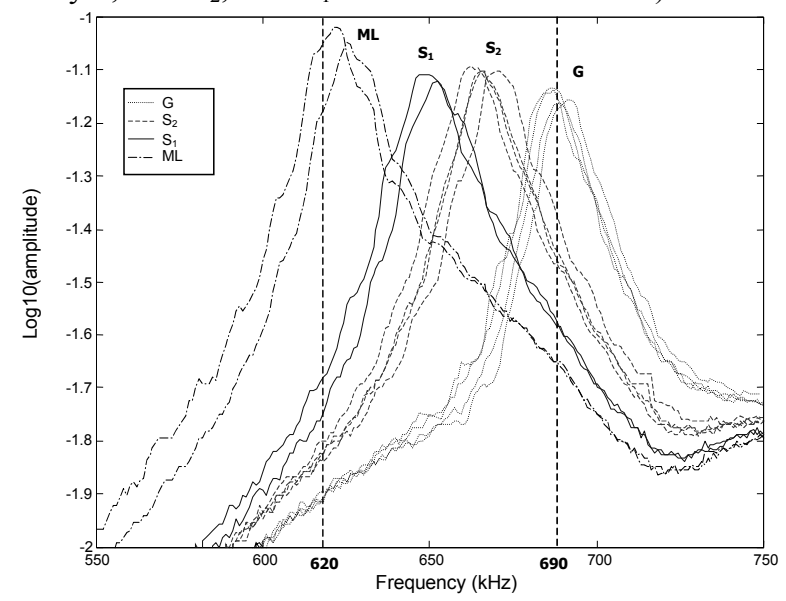

Fig. 2. Resonance spectra on the different cell wall layers of holm oak fibre.

One notices a small dispersion of the resonance frequencies within each cell wall layer and a drift toward higher values of frequency from the external layers toward the internal ones (ML toward G). This gives a qualitative information on stiffness: $G$ layer being the most rigid and middle lamella ML the least. These qualitative results are in agreement with the classic description of these layers (microfibril angle and crystalline cellulose content).

The two pictures presented in Fig 3 are obtained at fixed frequency for each one, and show how the contrast depends on the working frequency. At $620 \mathrm{kHz}$, the amplitude of the tip is maximum on the soft middle lamella, and low on the stiff $\mathrm{G}$ layer. At $690 \mathrm{kHz}$ the reverse contrast occurs.

The pictures show a large contrast between the wood cell wall layers, each layer being characterised by a relatively constant stiffness. The lateral resolution of the elastic images in the order of 20 to $50 \mathrm{~nm}$ and is determined by the radius of the contact area between the tip and sample.

Quantitative results obtained by comparison with standard samples, as explained above, are reported in Table 1, together with results obtained by Wimmer and Lucas (1997) and optimal values used by Harigton et al. (1998) or Watanabe and Norimoto (2000) to get realistic values of wood elastic modulus by models based on micro/macro approach.

Our results are rather similar to those obtained by nanoindentation. Wimmer et al. (1997) found large variations of elastic modulus in each cell wall layer for the different measurements ( 1 to 3 in proportion). We also found such variations (1 to 2 ) between different measurements on the same species (holm oak). But in a same exploration on one or two adjacent cells, variations are limited to a maximum of $20 \%$ in each cell wall. 
Table 1: Measured elastic properties of the cell layers, in GPa, expressed as the indentation modulus $\mathrm{E}^{*}=\mathrm{E} /\left(1-\mathrm{v}^{2}\right)$ or as the Young modulus $\mathrm{E}$ for extension experiments. $r=$ radius of curvature, *our experimental results corresponding to the presented curves and images, $* *$ other experimental results, $* * *$ measured on cell corner.

\begin{tabular}{|c|c|c|c|c|c|}
\hline & & ML & S1 & $\mathrm{S} 2$ & $\mathrm{G}$ \\
\hline holm oak wood fibre* & $\mathrm{r}=30 \mathrm{~nm}$ & $5-7$ & $8-9$ & $9-10$ & $10-12$ \\
\hline other holm oak wood fibre** & $\mathrm{r}=40 \mathrm{~nm}$ & 15 & & 20 & \\
\hline other holm oak wood fibre** & $\mathrm{r}=600 \mathrm{~nm}$ & $7-8$ & & $9-10$ & \\
\hline boco wood fibre** & $\mathrm{r}=400 \mathrm{~nm}$ & 10 & & $12-18$ & \\
\hline $\begin{array}{l}\text { Wimmer \& Lucas (1997) on } \\
\text { spruce wood }\end{array}$ & $\begin{array}{l}\text { pyramid } \\
\text { indentation }\end{array}$ & $5-15 * * *$ & & $7-22$ & \\
\hline Harrington (1998) & simulation & 18 & 53 & $\begin{array}{l}64 \\
\left(\mathrm{MFA}=0^{\circ}\right)\end{array}$ & \\
\hline Watanabe (2000) & simulation & 33 & 54 & $\begin{array}{l}64 \\
\left(\mathrm{MFA}=0^{\circ}\right)\end{array}$ & \\
\hline
\end{tabular}

It should be noted that: $\mathrm{i}$ - relative values between $\mathrm{ML}, \mathrm{S}_{1}$ and $\mathrm{S}_{2}$ are similar in nearly all the cases. ii- longitudinal elastic modulus estimated, both by indentation and atomic force microscopy in force modulation methods are strongly lower than values used in good models (up to five times less).

On one hand, some explanations can come from the actual values of MFA for the specimen used in experimental works (spruce in one case, holm oak in the other). Simulations using classical models (Watanabe \& Norimoto 2000) shows that elastic modulus can be divided by 5 or more when MFA growth from nearly zero to $35-40^{\circ}$. But normally $\mathrm{G}$ layer should have a very low MFA anyway.

On the other hand, elastic modulus in both cases were calculated with the assumption of elastic isotropic behaviour of the cell walls, which is surely not the case. Oliver and Pharr (1992), discussing about the use of nanoindentation for different materials, pointed out some discrepancy between elastic modulus measured by this method and reference values, for anisotropic materials (sapphire and quartz). They argued that in this case, using isotropic simplification can lead to values intermediate between elastic modulus in the two direction of anisotropy.

In the case of highly anisotropic fibre reinforced polymers like cell walls, a 10 ratio between elastic modulus in transverse and longitudinal direction is often found. So calculated values of elastic modulus using isotropic elastic contact (which is the case in both methods) can lead to values lying somewhere between one and one tenth of the longitudinal expected one.

Basic mechanical analysis are needed to fully understand what is really measured in both methods for cell wall material. Both measurements on transverse cell section, like in this studies, and longitudinal (radial or tangential) cell section will be necessary to estimate elastic modulus in the two main direction of anisotropy in the cell walls at the same time. 

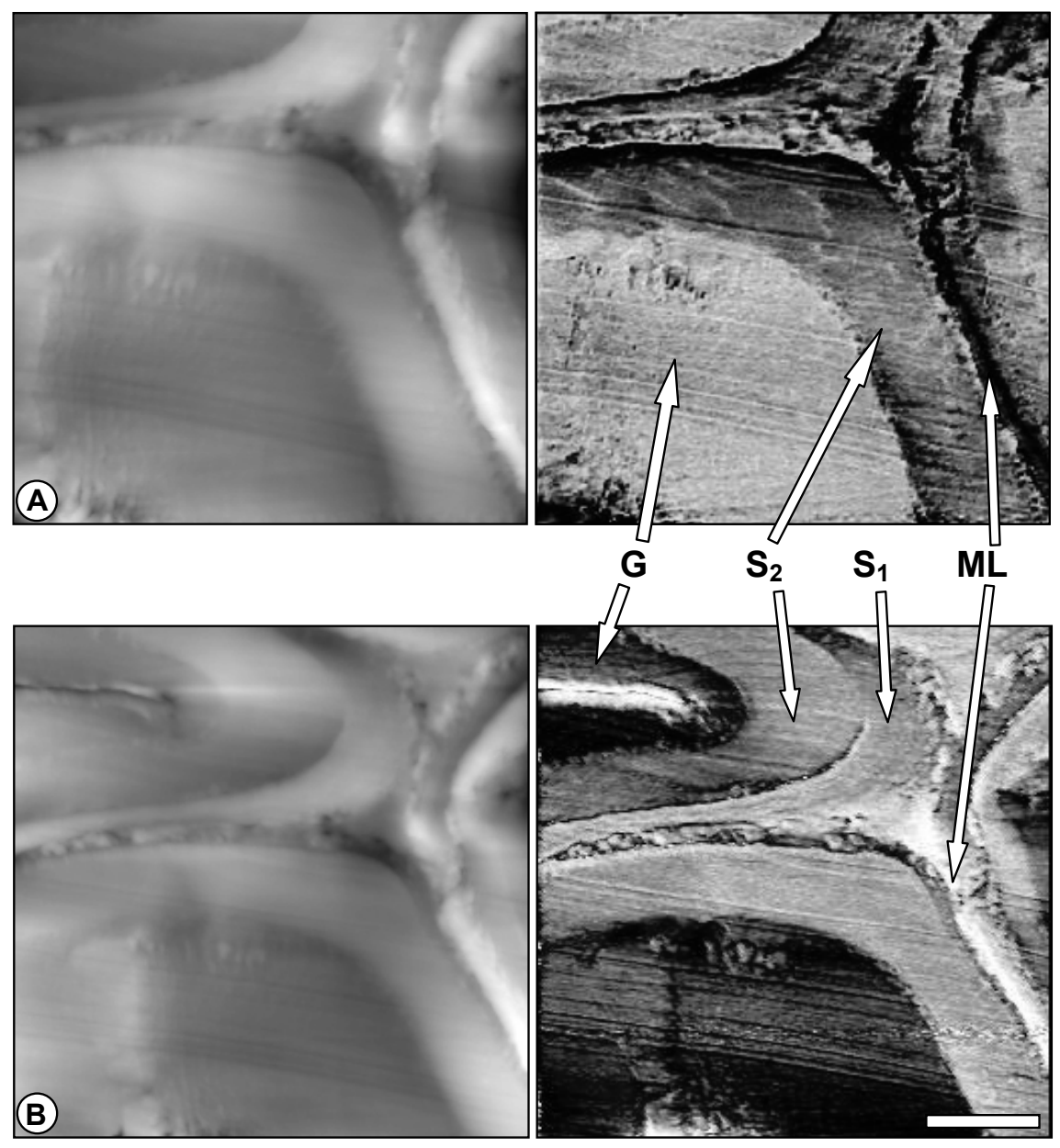

Fig 3. Cell wall layers of oak tension wood. In topographic images (on the left), grey levels span a total of $300 \mathrm{~nm}$. The "elasticity" images (on the right) were made at $620 \mathrm{kHz}$ (A) and $690 \mathrm{kHz}$ (B). At $620 \mathrm{kHz}$, the lighter zone corresponds to the stiffer cell wall layers, while the reverse occurs at $690 \mathrm{kHz}(\mathrm{B})$. Scale bar $=2 \mu \mathrm{m}$. Anyway both techniques have a high potential in the future to investigate mechanical properties at the cell wall levels for absolute values or for comparisons between walls or between cells representatives of different cases (juvenile/mature ; spring/summer or normal/reaction wood).

They also seems complementary. Nanoindentation use very hard (diamond) tips which geometry is well know and rather stable. It has a higher potential to realise quickly a good absolute estimate of local elastic properties on a given set of 
positions. Atomic force microscopy in force modulation mode use softer (silica) tips which will be more or less quickly blunted during operations. Probably using blunted tips with 100 to $500 \mathrm{~nm}$ radius will be a better solution to limit variations in an image acquisition. It has a higher ability to perform high resolution images of elastic constant for cell walls with a reliable relative estimation of elasticity between regions.

\section{CONCLUSION}

The modulation force microscopy was used to study mechanical properties of the cell wall layer at a nanometric level. High resolution qualitative images are relatively easy to obtain, nevertheless, the quantification of the mechanical behaviour is only approximate, because on the simplifying hypothesis (Hertz or DMTcontact on homogeneous isotropic material) whose limits are still to be analysed.

On thick layers as the $\mathrm{G}$ or $\mathrm{S}_{2}$ layers, the contact surface (radius $\sim 30 \mathrm{~nm}$ ) is small compared to the layer width, and the measurements are the most reliable, but for thinner layers, as the middle lamella or $\mathrm{S}_{1}$ layer, the boundary effect may be important, and the interaction of the tip with adjacent layers are to be taken into account.

\section{REFERENCES}

Cave, I.D. 1968. The anisotropic elasticity of the plant cell wall. Wood Science and Technology, 2: 268-278.

Dupas, E., G. Gremaud, A. Kulik \& J.L. Loubet. 2001. High-frequency mechanical spectroscopy with an atomic force microscope. Rev. Sci. Instrum., 72: 3891-3897.

Harrington, J.J., R. Booker \& R.J. Astley. 1998. Modelling the elastic properties of softwood (Part I : The cell-wall lamellae). Holz als Roh- und Werkstoff, 56: $37-41$.

Maugis, D. 2000. Contact Adhesion and Rupture of Elastic Solids. Springer, Berlin.

Oliver, W.C. \& G.M. Pharr. 1992. An improved technique for determining hardness and elastic modulus using load and displacement sensing indentation experiments. J. Mater. Res., 7: 1564-1583.

Pietrement, O. \& M. Troyon. 2000a. General equations describing elastic indentation depth and contact stiffness versus load. Journal of Colloid and Interface Science, 226: 166-171.

Pietrement, O. \& M. Troyon. 2000b. Quantitative elastic modulus measurements by magnetic force modulation microscopy. Tribology letters, 9: 77-87.

Rabe, U., K. Janser \& W. Arnold. 1996. Vibration of free and surface coupled atomic force microscope: theory and experiments. Rev. Sci. Instrum., 67: 3281-3293.

Rabe, U., J. Turner \& W. Arnold. 1998. Analysis of the high-frequency response of atomic force microscope cantilever. Applied Physic, A66: S277-282.

Sasaki, S., M. Morimoto, H. Haga, K. Kawabata, E. Ito, T. Ushiki, K. Abe \& T. Sambongi. 1998. Elastic propeties of living fibroplastes as imaged using 
force modulation mode in atomic force microscopy. Arch. Histol. Cytol., 61: 57-63.

Watanabe, U. \& M. Norimoto. 2000. Three Dimensional Analysis of Elastic Constants of the Wood Cell Wall. Wood Research, 87: 1-7.

Wimmer, R. \& B.N. Lucas. 1997. Comparing mechanical properties of secondary wall and cell corner middle lamella in spruce wood. IAWA bulletin, 18: 7788.

Wimmer, R., B.N. Lucas, T. Tsui \& W.C. Oliver. 1997. Longitudinal hardness and Young's modulus of spruce tracheid secondary walls using nanoindentation technique. Wood Science and Technology, 31: 131-141.

Yamamoto, H., F. Sassus, M. Ninomiya \& J. Gril. 2001. Model of anisotropic swelling and shrinking process of wood. Part 2. A simulation of shrinking wood. Wood Science and Technology, 35: 167-181.

Yamanaka, K. \& S. Nakano. 1996. Ultrasonic atomic force microscopy with overton excitation of cantilever. Jpn. J. Appl. Phys., 35: 3787-3792.

Yamanaka, K. \& S. Nakano. 1998. Quantitative elasticity evaluation by contact resonance in an atomic force microscope. Applied Physic, A: S313-S317. 